\title{
The improvement of treatment efficacy of gastropathy associated with the use of nonsteroidal anti-inflammatory drugs in Helicobacter pylori-negative patients with osteoarthritis
}

\author{
Antonina V. Antonenko ${ }^{\star 1}$, Tetyana V. Beregova ${ }^{2}$ \\ ${ }^{1}$ Department of Internal Medicine No. 3, Bogomolets National Medical University, T. Shevchenko 13, 01601, Kyiv, Ukraine \\ ${ }^{2}$ Department of Pharmaco-Physiology, Taras Shevchenko National University of Kyiv, Vladimirskaya 64, 01601, Kyiv, Ukraine
}

\section{ARTICLE INFO \\ Received 07 November 2014 Accepted 12 December 2014}

\section{Keywords:}

NSAID-gastropathy,

NSAID-enteropathy, colonic microbiota, pantoprazole, probiotics.

\begin{abstract}
Among the more common side effects of osteoarthritis treatment are NSAID-gastropathy and NSAID-enteropathy. NSAIDs can cause direct injury to colon tissue and also impair synthesis of prostaglandins, reduce mucosal integrity, increase permeability and promote an influx of bacteria and toxins. Alterations in gastrointestinal permeability are considered as an initial step in the development of lesions of the gastric mucosa such as erosions and ulcers. The mechanisms underlying the ability of NSAIDs to cause ulceration in the stomach and proximal duodenum are well understood and this injury can be largely be prevented through suppression of gastric acid secretion. However, our work showed that 28-day administration of the anti-secretory preparation pantoprazole ( $20 \mathrm{mg} 2$ times per day) resulted in a statistically significant increase of dysbiosis. Monitoring of patients with osteoarthritis who used NSAIDs for more than three months showed that, in comparison to the situation before the beginning of treatment, changes in colonic microbiota were present. Multiprobiotic "Symbiter" acidophilic concentrated" introduced simultaneously with pantoprazole during 20 days prevented formation of dysbiotic changes and led to the quicker healing of gastric mucous healing, in comparison with patients who used only pantoprazole alone. Moreover, it brought about total healing of the gastric mucosa within 4 weeks from the beginning of treatment.
\end{abstract}

\section{INTRODUCTION}

Osteoarthritis (OA), the most prevalent disease in our society, is a slowly progressive degenerative disease characterized by gradual loss of articular cartilage. It results in joint stiffness and dysfunction, but the main problem for most patients is pain, loss of function and social incapacity [6].

NSAIDs are one of the most widely used medications worldwide. Among the more common side effects of NSAID administration are NSAID-gastropathy and NSAID-enteropathy. The mechanisms underlying the ability of NSAIDs to cause ulceration in the stomach and proximal duodenum are well understood, and this injury can be largely be prevented through suppression of gastric acid secretion (mainly with proton pomp inhibitors (PPI)) [3,6]. At the same time,

\section{Corresponding author}

e-mail: tonyaant@yandex.ru

tel.: +38 0938850910 the influence of NSAIDs on the more distal regions of the gastrointestinal tract and on colonic microbiota are not well studied. It is known that in animal models, NSAIDenteropathy is accompanied by shifts in numbers and types of intestinal bacteria [5]. NSAIDs can cause direct injury to colon tissue and also impair synthesis of prostaglandins, reduce mucosal integrity, increase permeability and promote an influx of bacteria and toxins. Alterations in gastrointestinal permeability are considered as an initial step in the development of lesions of gastric mucosa such as erosions and ulcers [4]. Probiotics stabilize the intestinal barrier function in vitro, in animal models and in clinical studies. PPI that are widely used in clinical practice as basic remedies for treatment of acid dependent diseases (peptic ulcers of stomach and duodenum, symptomatic erosions and ulcers, pancreatitises, gastroesophagal reflux disease etc.) aggravate the dysbiosis [1]. The peculiarities of colonic microbiota and its correlation with the severity of gastric 
lesions in patients with osteoarthritis who used NSAIDs for more than three months has not been studied before. That is why the aim of our work was to investigate the influence of colonic microbiota on the severity of gastric lesions, to determine a correlation between the intensity of dysbiosis, age and the severity of gastric lesions, and to see whether the treatment of NSAIDs-associated gastric mucosa (GM) lesions could be optimized with the help of multiprobiotic "Symbiter® acidophilic"

\section{MATERIALS AND METHODS}

In this study, we examined 75 Helicobacter pylori (Hp) negative patients with osteoarthritis who used non-selective NSAIDs for more than three months. The mean age of these patients was $63,2 \pm 6,0$ years. For all of these individuals, gastroscopy and analysis of fecal microflora were performed. The gastroscopy was made with the help of fibrogastroscope FUJINON FG-1Z. Quantitative indices of fecal microflora were studied by means of inoculating $1 \mathrm{ml}$ of each dilution (1:10) on differential-diagnostic medium: Endo's, Ploskiriev's and BCA to identify pathogenic enterobacteria; bile-saline agar and Saburo's medium to determine staphylococci and fungi; Endo's and Simonce's citrate to discover colibacillus and opportunistic enterobacteria; 5\% blood agar and EDDS medium to identify enterococci; Blaurok's medium for bifidobacteria and MKS for lactobacilli. In haemanalysis, special attention was given to the level of red blood cells and haemoglobin. Patients with endoscopically diagnosed NSAIDs-gastropathy (60 patients) were randomized, and placed into two equal groups. The patients from the first (control) group, during the 28 days of the study, were treated with the use of pantoprazole ("KRKA", Slovenia) at $20 \mathrm{mg} \times 2$ times daily. Patients from the second (trial) group, again treated with pantoprazole at $20 \mathrm{mg}$ x 2 times daily, also simultaneously received multiprobiotic "Symbiter ${ }^{\circledR}$ acidophilic concentrated" (Firm OD Prolisok Ltd) in dose $0,14 \mathrm{ml} / \mathrm{kg}$ per day during the first 20 days.

Symbiter is a concentrated fluid biomass of bioplasts that are a symbiosis of 14 microorganism strains. One daily dose (10 ml) of Symbiter consists of, in $\mathrm{CFU} / \mathrm{cm}^{3}$, no less: Lactobacillus and Lactococcus $-6.0 \times 1010$, Propionic bacterium $-3.0 \times 10^{10}$, Bifidobacterium $-1.0 \times 1010$ and Acetic bacterium $-1.0 \times 10^{6}$.

After one month, we repeated all analysis. All procedures received local ethics committee approval (№ 78 from 26.03.2014).

\section{STATISTICAL ANALYSIS}

The normal distribution of the studied parameter for each sampling was checked using Pearson's chi-squared test. Moreover, average value (M) error and standard deviation (SD) were calculated to discover significant changes of age in the patient groups. The distribution of data was evaluated by way of Pearson's chi-squared test $\left(\mathrm{x}^{2}\right)$, and the linear connection between parameters was evaluated using Spearman rank correlation coefficient. What is more, sampling comparison was performed using the unpaired Student's t-test, while differences among values were considered statistically significant at $\mathrm{p}<0.05$.

\section{RESULTS}

Among the 75 patients who were examined, lesions of the GM were discovered in 60 patients. These lesions were superficial erosions with mild erythema and petechiae. In 15 patients, visible changes of GM were absent. Of note, histologicaly NSAIDs-gastropathy is characterized by peculiarities that are typical to chemical gastritis: foveolar hyperplasia, low activity of gastritis and pit elongation etc. Interestingly, foveolar hyperplasia, one of the typical histological characteristic of chemical gastritis, was present only in $62 \%$ of all patients. Changes in colonic microbiota were also observed in all patients who used NSAIDs for more than three months. The results of our analysis of the dependence of the decreasing of Bifidobacterium and the age of the patients in our study group is shown in Table 1.

Table 1. Statistical relationships between the concentration of Bifidobacterium and the age of the patients

\begin{tabular}{|c|c|c|c|c|}
\hline \multirow{2}{*}{ Age of the patient } & \multicolumn{4}{|c|}{ Concentration of Bifidobacterium } \\
\cline { 2 - 5 } & $10^{5}$ & $10^{6}$ & $10^{7}$ & $\geq 10^{8}$ \\
\hline$<60$ & 0 & 1 & 13 & 13 \\
\hline $61-70$ & 0 & 8 & 16 & 12 \\
\hline$>70$ & 2 & 4 & 5 & 1 \\
\hline \multicolumn{5}{|c|}{$r=-0.45 ; *-p$-value $=0,004$} \\
\hline
\end{tabular}

Our results reveal that the level of Bifidobacterium is dependent upon the patient's age $(\mathrm{r}=-0.45 ; *-\mathrm{p}$-value $=$ 0,004).

We also analysed the dependence of the decrease of Lactobacillus with the age of the patients (Table 2).

Table 2. Statistical relationships between the concentration of Lactobacillus and the age of the patients $(n=75)$

\begin{tabular}{|c|c|c|c|c|}
\hline \multirow{2}{*}{ Age of the patient } & \multicolumn{4}{|c|}{ Concentration of Lactobacillus } \\
\cline { 2 - 5 } & $10^{5}$ & $10^{6}$ & $10^{7}$ & $\geq 10^{8}$ \\
\hline$<60$ & 1 & 8 & 15 & 3 \\
\hline $61-70$ & 3 & 6 & 23 & 5 \\
\hline$>70$ & 1 & 6 & 4 & 0 \\
\hline$r=-0,20 ; p$-value $>0,05$ \\
\hline
\end{tabular}

Here, it is seen that the correlation between Lactobacillus and age is not observed $(r=-0,20, p>0,05)$.

In our study, we examined in the test group, the effectiveness of a combined treatment (pantoprazole $20 \mathrm{mg}$ x 2 times daily and multiprobiotic "Symbiter ${ }^{\circledR}$ acidophilic concentrated" $0,14 \mathrm{mg} / \mathrm{kg}$ per day during 20 days). The results of this can be seen in Table 3. Accordingly, over one month, in the control group, erosive lesions of GM were observed in 16 patients (over the length of the study, the number of erosions in these patients significantly decreased, but, nevertheless, they did not disappear). In the test group, in all patients, erosions were absent. 
Table 3. The evaluation of the effectiveness of a combined method of treatment of patients with NSAIDs-gastropathy $(n=60)$

\begin{tabular}{|c|c|c|c|c|c|c|}
\hline \multirow[b]{2}{*}{$\begin{array}{l}\text { Indicator } \\
\text { (number } \\
\text { of erosions) }\end{array}$} & \multicolumn{3}{|c|}{ Control group $(n=30)$} & \multicolumn{3}{|c|}{ Test group $(n=30)$} \\
\hline & \begin{tabular}{|r}
$\begin{array}{r}\text { Befor } \\
\text { treatme }\end{array}$ \\
$\mathrm{nu}$ \\
$\mathrm{p}$
\end{tabular} & $\begin{array}{l}\text { After } \\
\text { eatment } \\
r \text { of } \\
\text { its } \\
\end{array}$ & $\mathrm{P}$ & $\begin{array}{r}\begin{array}{r}\text { Befor } \\
\text { treatme }\end{array} \\
\mathrm{nu} \\
\mathrm{p}\end{array}$ & $\begin{array}{l}\text { After } \\
\text { reatment } \\
\text { er of } \\
\text { nts }\end{array}$ & $\mathrm{P}$ \\
\hline Absent & - & 14 & \multirow{3}{*}{$\begin{array}{c}x^{2}=30,1 \\
p<0,0001\end{array}$} & - & 30 & \multirow{3}{*}{$\begin{array}{c}x^{2}=60,0 \\
p<0,0001\end{array}$} \\
\hline$<3$ & 14 & 16 & & 22 & - & \\
\hline$>3$ & 16 & - & & 8 & - & \\
\hline
\end{tabular}

In both groups, we compared the influence of the treatment on the dysbiosis within the study group (Table 4 and Table 5).

Table 4. The influence of treatment: patients with NSAIDsgastropathy and Lactobacillus levels $(n=60)$

\begin{tabular}{|c|c|c|c|c|c|c|}
\hline \multirow[b]{2}{*}{$\begin{array}{c}\text { Indicator } \\
\text { (concentration } \\
\text { of Lactobacillus) }\end{array}$} & \multicolumn{3}{|c|}{ Control group $(n=30)$} & \multicolumn{3}{|c|}{ Test group $(n=30)$} \\
\hline & \begin{tabular}{|r|}
$\begin{array}{r}\text { Befor } \\
\text { treatme }\end{array}$ \\
$\mathrm{nu}$ \\
$\mathrm{p}$
\end{tabular} & $\begin{array}{l}\text { After } \\
\text { eatment } \\
\text { er of } \\
\text { tts } \\
\end{array}$ & $P$ & $\begin{array}{r}\begin{array}{r}\text { Befor } \\
\text { treatme }\end{array} \\
\mathrm{nu} \\
\mathrm{p}\end{array}$ & $\begin{array}{l}\text { After } \\
\text { reatment } \\
\text { er of } \\
\text { nts }\end{array}$ & $P$ \\
\hline $10^{5}$ & 5 & 3 & \multirow{4}{*}{$\begin{aligned} x^{2} & =4,075 \\
p & =0.25\end{aligned}$} & 6 & 24 & \multirow{4}{*}{$\begin{array}{l}x^{2}=23,06 \\
p<0,0001\end{array}$} \\
\hline $10^{6}$ & 9 & 16 & & 17 & 6 & \\
\hline $10^{7}$ & 15 & 11 & & 7 & 0 & \\
\hline$\geq 10^{8}$ & 1 & 0 & & 0 & 0 & \\
\hline
\end{tabular}

Table 5. The influence of treatment: patients with NSAIDsgastropathy and Bifidobacterium levels $(n=60)$

\begin{tabular}{|c|c|c|c|c|c|c|}
\hline \multirow[b]{2}{*}{$\begin{array}{c}\text { Indicator } \\
\text { (concentration } \\
\text { of Bifidobacterium) }\end{array}$} & \multicolumn{3}{|c|}{ Control group $(n=30)$} & \multicolumn{3}{|c|}{ Test group $(n=30)$} \\
\hline & $\begin{array}{r}\begin{array}{c}\text { Before } \\
\text { treatment }\end{array} \\
\begin{array}{r}\text { numb } \\
\text { pati }\end{array}\end{array}$ & $\begin{array}{l}\begin{array}{c}\text { After } \\
\text { treatment }\end{array} \\
\text { er of } \\
\text { ents }\end{array}$ & $P$ & \begin{tabular}{|r|}
$\begin{array}{c}\text { Before } \\
\text { treatment }\end{array}$ \\
$\begin{array}{r}\text { numb } \\
\text { pati }\end{array}$ \\
\end{tabular} & \begin{tabular}{|l|}
$\begin{array}{c}\text { After } \\
\text { treatment }\end{array}$ \\
er of \\
ents
\end{tabular} & $P$ \\
\hline 105 & 1 & 1 & \multirow{4}{*}{$\begin{array}{c}x^{2}=3,727 \\
p=0.29\end{array}$} & 1 & 0 & \multirow{4}{*}{$\begin{array}{l}x^{2}=38,19 \\
p<0,0001\end{array}$} \\
\hline 106 & 8 & 14 & & 5 & 1 & \\
\hline 107 & 17 & 14 & & 13 & 2 & \\
\hline$\geq 108$ & 4 & 1 & & 11 & 27 & \\
\hline
\end{tabular}

The data from the tables show that in patients who were treated with IPP alone (control), dysbiosis has been enhanced.

Thus, investigations aimed at analyzing effect of multiprobiotic Symbiter on the improvement of treatment of NSAID-gastropathy in patients with osteoarthritis who used NSAIDs for more than three months show that Symbiter accelerates the healing of gastric mucous lesions in such patients. PPI that are widely used for the treatment of NSAID-gastropathy, when used alone, aggravate the dysbiosis. Symbiter is able to stabilize effectively colonic microflora and normalize balance between main species of obligatory and opportunistic microflora. This leads to the quicker healing of lesions of gastric mucosa.

\section{DISCUSSION}

The results of our study reveal that in all patients with osteoarthritis who have been taking NSAIDs for more than three months, changes in colonic microflora occur. Interestingly, the different species of microbiota are characterized by having different correlation rates with age and the severity of gastric lesions. According to the Maastricht IV guidelines, PPI should be prescribed for patients with NSAIDs-gastropathy for at least 28 days. In our experiment, the long-term introduction (28 days) of the anti-secretory preparation pantoprazole resulted in a significant enhancement of dysbiosis that did not lead to the quick healing of gastric lesions. These results agree with that of other investigators $[3,4]$.

Multiprobiotic "Symbiter ${ }^{\circledR}$ acidophilic concentrated" introduced simultaneously with pantoprazole for a period of 20 days prevented the enhancement of dysbiosis. This led to the quicker healing of gastric mucous lesions, in comparison with patients who were prescribed with and utilized pantoprazole alone. We suggest that one of the mechanisms of the protective action of Symbiter is its normalization of the colonic microbiocenosis, and, hence, as seen in our results, the healing of gastric lesions came about in all our test group $(n=30)$.

The protective functions of normoflora are not limited only by an antagonism to pathogenic agents. Lactobacillus diminishes the level of pro-inflammatory cytokines that are increased when gastric ulcers and erosions occur. Moreover, it increases the basal gastric mucosal $\mathrm{PGE}_{2}$ level that has protective effects against various gastric injuries, and it induces the mucin gene expression in gastric epithelial cell lines that leads to the enhancement of the mucus-secreting layer in gastric mucosa and the healing of erosions and ulcers [2].

\section{CONCLUSION}

Our findings show that changes in the colonic microbial community structure correlate with the intensity of the lesions of gastric mucosa, and with the age in patients with NSAIDs-gastropathy. The inclusion of multiprobiotic in the general scheme of treatment of NSAIDs-gastropathy eliminates the detected dysbiosis, and leads to the total healing of gastric mucosa. In our study, within the test group this came about in just over four weeks from the beginning of treatment. Thus, we recommend the inclusion of multiprobiotic "Symbiter ${ }^{\circledR}$ acidophilic" concentrated in the general scheme of the treatment of NSAIDs-gastropathy.

\section{REFERENCES}

1. Fossmark R., Johnsen G., Johanessen E.: Rebound acid hypersecretion after long-term inhibition of gastric acid secretion. Aliment Pharmacol Ther., 21, 2, 2005.

2. Lam E. et al.: Enhancement of gastric mucosal integrity by Lactobacillus rhamnosus GG. Life Sci., 80, 2007.

3. Muratoglu G. et al.: Protective effect of famotidine, omeprazole and melatonin against acetylsalicytic acid-induced gastric damage in rats. Dig Dis Sci., 46, 2001.

4. Senol A. et al. Effect of probiotics on aspirin-induced gastric mucosal lesions. Turk J Gastroenterol., 22, 1, 2011.

5. Syer S, Wallace J. Environmental and NSAID-enteropathy: dysbiosis as a common factor. Curr Gastroenterol Rep., 16, 2014

6. Wallace J. NSAID gastropathy and enteropathy: distinct pathogenesis likely necessitates distinct prevention strategies. Br J Pharmacol., $165,2012$. 